\title{
The Impact of Seasonality and Land Cover on the Consistency of Relationship between Air Temperature and LST Derived from Landsat 7 and MODIS at a Local Scale: A Case Study in Southern Ontario
}

\author{
Michael Burnett and Dongmei Chen *(1)
}

check for

updates

Citation: Burnett, M.; Chen, D. The Impact of Seasonality and Land Cover on the Consistency of Relationship between Air Temperature and LST Derived from Landsat 7 and MODIS at a Local Scale: A Case Study in Southern Ontario. Land 2021, 10, 672. https:// doi.org/10.3390/land10070672

Academic Editor: Adrianos Retalis

Received: 17 May 2021

Accepted: 23 June 2021

Published: 26 June 2021

Publisher's Note: MDPI stays neutral with regard to jurisdictional claims in published maps and institutional affiliations.

Copyright: (c) 2021 by the authors. Licensee MDPI, Basel, Switzerland. This article is an open access article distributed under the terms and conditions of the Creative Commons Attribution (CC BY) license (https:// creativecommons.org/licenses/by/ $4.0 /)$.
Department of Geography and Planning, Queen's University, Kingston, ON K7L 3N6, Canada; 19mdmb@queensu.ca

* Correspondence: chendm@queensu.ca

\begin{abstract}
Land surface temperature (LST) and air temperature $\left(\mathrm{T}_{\text {air }}\right)$ have been commonly used to analyze urban heat island (UHI) effects throughout the world, with noted variations based on vegetation distribution. This research has compared time series LST data acquired from the Moderate Resolution Imaging Spectroradiometer (MODIS) platforms, Landsat 7 Enhanced Thematic Mapper $(\mathrm{ETM}+)$ and $\mathrm{T}_{\text {air }}$ from weather stations in the Southern Ontario area. The influence of the spatial resolution, land cover, vegetated surfaces, and seasonality on the relationship between LST and in situ $\mathrm{T}_{\text {air }}$ were examined. The objective is to identify spatial and seasonal differences amongst these different spatial resolution LST products and $\mathrm{T}_{\mathrm{air}}$, along with the causes for variations at a localized scale. Results show that MODIS LST from Terra had stronger relationships with Landsat 7 LST than those from Aqua. $\mathrm{T}_{\text {air }}$ demonstrated weaker correlations with Landsat LST than with MODIS LST in sparsely vegetated and urban areas during the summer. Due to the winter's ability to smooth heterogenous surfaces, both LST and $\mathrm{T}_{\text {air }}$ showed stronger relationships in winter than summer over every land cover, except with coarse spatial resolutions on forested surfaces.
\end{abstract}

Keywords: land surface temperature; Landsat 7 Enhanced Thematic Mapper; MODIS; air temperature; Southern Ontario; land cover; seasonality; scale

\section{Introduction}

Land surface temperature (LST) and air temperature $\left(\mathrm{T}_{\text {air }}\right)$ are useful for assessing and mapping earth surface and near-surface thermal conditions using information related to sensible and latent heat fluxes [1]. In urban environments, increased impervious surfaces, reduced vegetated areas with canopy cover, and atmospheric pollution affect the local LST and $\mathrm{T}_{\text {air }}$ [2]. As a result, heat absorption from numerous types of urban surfaces and anthropogenic activities lead to urban heat island (UHI) effects with rising LST and $\mathrm{T}_{\text {air }}$ [3]. Therefore, examining the temporal and spatial changes of LST and $\mathrm{T}_{\text {air }}$ is commonly used to study the impact and footprint of UHI caused by urbanization [4-6].

$\mathrm{T}_{\mathrm{air}}$ is often measured through weather stations. Canopy cover, wind, humidity, and other atmospheric properties affect the local $\mathrm{T}_{\text {air }}$ at each station, and vegetated land cover distributions influence $\mathrm{T}_{\text {air }}$ with its microclimatic effects, along with rapid cool and warm air advections [7]. Although $\mathrm{T}_{\text {air }}$ measured at sparse weather stations often has high accuracy and temporal frequencies, its application in assessing UHI is dependent upon its location and the surrounding surface characteristics. For example, measuring $\mathrm{T}_{\text {air }}$ at airport locations found no evidence of correlation with population accumulation [8], while using in situ stations located within urban centers provides contrasting results [9].

Satellite-based LST provides comprehensive earth surface temperature data at different spatial resolutions, with different temporal resolutions. Comparing with ground-based 
$\mathrm{T}_{\text {air }}$, satellite-based LST has the advantage of detailed spatial coverage, although its temporal resolution is often limited. For example, the most commonly used Moderate Resolution Imaging Spectroradiometer (MODIS) LST data often have a coarse spatial resolution of 1 $\mathrm{km}$ with daily overpass frequency, which would reveal intra-annual dynamics and overall patterns throughout large areas [10]. However, its coarse spatial resolution often results in mixed pixels, containing more than one land cover in heterogenous landscapes [11,12]. Alternatively, finer spatial resolution sensors, such as Landsat 7 Enhanced Thematic Mapper (ETM+), have the ability to resolve complex land cover patterns, reduce mixed pixels, add surface detail, and validate coarse resolution maps [13]. Although many satellite-based LST products are available, there seems to be few direct comparisons of different LST products at local regional levels.

Previous studies have compared ground-measured $\mathrm{T}_{\text {air }}$ with satellite-based LST at global and continental scales [14-16]. By comparing the LST from MODIS, AVHRR, and (A)ATSR, researchers have found that MODIS LST has the highest agreement with $\mathrm{T}_{\text {air }}[15,17,18]$. Vegetation, land cover, terrain, and seasonality would impact the correlation between MODIS LST and $\mathrm{T}_{\text {air }}[15,16,19-21]$. However, most of those studies are based on MODIS or similar coarse resolution-based LST products, not on fine-resolution LST products such as Landsat ETM+, especially at the local scale. Limited studies have been conducted to investigate the relationship between surface temperature from Landsat TM and $\mathrm{T}_{\text {air }}$ during winter nights [22]. In UHI studies, the sparse $\mathrm{T}_{\text {air }}$ measures from limited weather stations cannot provide the detailed spatial variation and change of urban thermal surface. Therefore, fine-resolution LST products would provide an additional dimension for understanding the temperature variability in an urban setting. In addition, the recent availability of using Google Earth Engine (GEE) to simplify methods of obtaining LST from Landsat imagery makes an extensive LST comparison acquired at different scales easily accessible.

This study is intended to compare LST products derived from Landsat 7 and MODIS and examine the impact of seasonality and land cover on the relationship between LST and $\mathrm{T}_{\mathrm{air}}$ at a local scale. The key questions addressed in this study are: (1) What is the difference between LST data derived from MODIS at $1 \mathrm{~km}$ resolution and Landsat 7 ETM+ at $30 \mathrm{~m}$ resolution? (2) How does the seasonality, land cover, and spatial resolution impact the relationship between satellite-derived LST and $\mathrm{T}_{\text {air }}$ at a local scale?

\section{Materials and Methods}

\subsection{Study Area}

Milton, Ontario, Canada, is used as the central point to determine the study area. Milton is the fastest-growing community in Ontario, and the sixth overall throughout Canada amongst the most rapidly urbanizing communities nationwide. To study the relationship of satellite-based LST and $\mathrm{T}_{\text {air }}$, we need to collect ground air temperature data from weather stations. To maximize availability of in situ data from weather stations near GTA and its surrounding area, a $100 \mathrm{~km}$ buffer around its urban core was used as the study area, as shown in Figure 1. There are 46 weather stations located in the study area (marked in red dots in Figure 1) and included in the analysis.

The area has a population greater than 7 million people, representative of the most populated area in Canada. It has a humid continental climate with short spring and autumn seasons. The annual average temperature of the region is around $9{ }^{\circ} \mathrm{C}$, and the annual average precipitation is around $830 \mathrm{~mm}$. Precipitation in all months is quite consistent, with mainly snow during the winter. The average minimum temperatures in December January, February, and March are below zero, with the average minimum temperature of around $-7^{\circ} \mathrm{C}$ in January and February. From the end of March, the temperature rises, and usually reaches to the average maximum temperatures of $24^{\circ} \mathrm{C}, 27^{\circ} \mathrm{C}$, and $26^{\circ} \mathrm{C}$ in June, July, and August, and then declines. Average maximum temperatures in the summer can range from $23{ }^{\circ} \mathrm{C}$ to $31^{\circ} \mathrm{C}$, with moderate to high humidity due to the lake effect. Snow can fall in early spring or late fall, but usually melts quickly in spring and fall. 


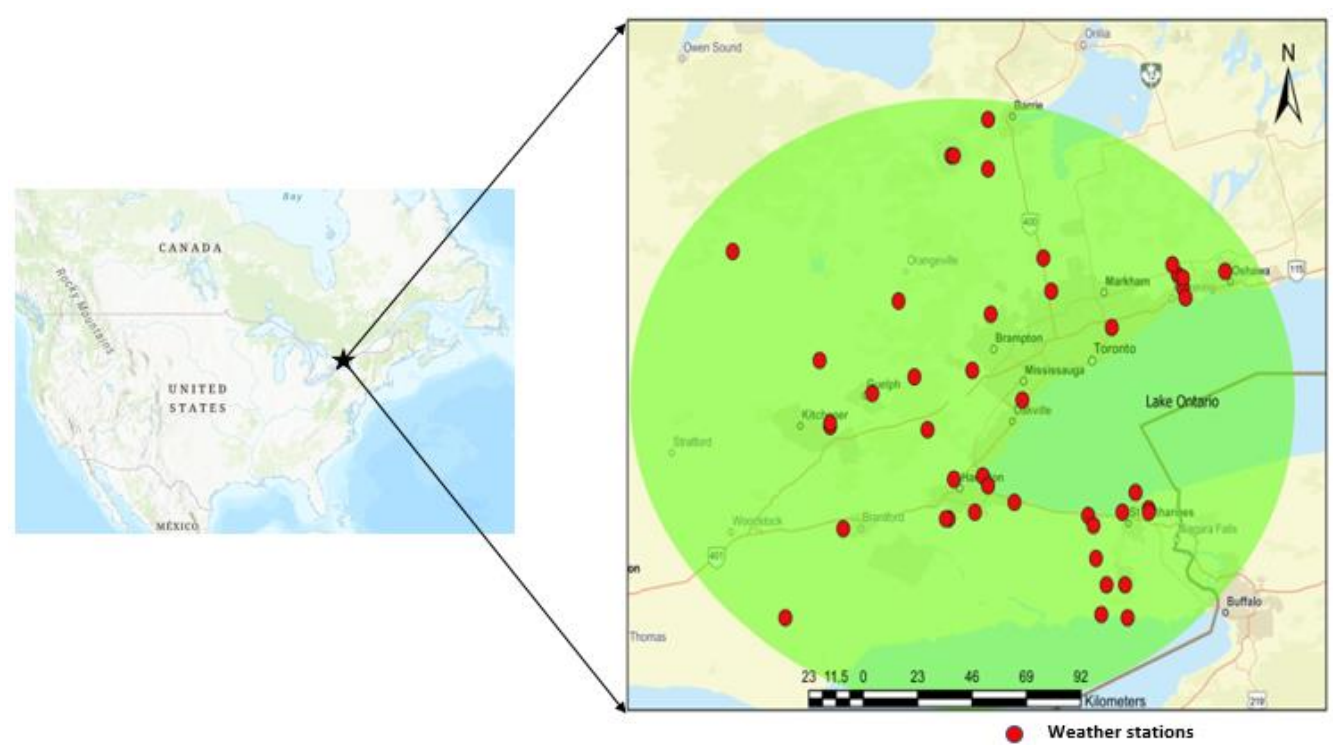

Figure 1. The locations of the study area and all the weather stations used in this study. The area in green represents the $100 \mathrm{~km}$ buffer around Milton, encompassing the populated Southern Ontario region. Milton is located at $79.9^{\circ} \mathrm{W}, 43.5^{\circ} \mathrm{N}$.

\subsection{In Situ Meteorological Data}

Hourly $\mathrm{T}_{\text {air }}$ data was acquired from the Climate Services department of the Government of Canada's Ministry of Environment and Climate Change. The metadata for each weather station, such as the geographical coordinates, instrument parameters, and station ID, were also obtained. In order to maximize the database, all stations within the study area, including the ones which were only temporarily operational and contain data gaps, are included.

For use in a daytime comparison with LST products, the data collected at the nearest hour to the time of acquisition for all products from each satellite platform was used. The LST data derived from Landsat 7 ETM+ products within the area were all obtained within twenty minutes of 16:00. The fluctuations with the overpass time of each of the MODIS platforms results in far more complex comparisons. Both satellites capture daily data throughout a $2.5 \mathrm{~h}$ overpass window over the Milton area. In order to present data at the nearest hour to the overpass time of each satellite, the MODIS Terra data is compared with the 10:00, 11:00, and 12:00 $\mathrm{T}_{\text {air }}$ measurements, while the Aqua data is compared to the 12:00, 13:00, and 14:00 data. In addition, due to the processing employed to derive the level 2 MODIS LST data, both platforms are also compared with the daily average and maximum $\mathrm{T}_{\text {air }}$ data.

\subsection{Land Cover Data}

Raster and vector land cover maps were provided by the Southern Ontario Land Resource Information System (SOLRIS). An accuracy assessment conducted in the same area as this analysis has an overall accuracy of $93 \%$, captured by fuzzy error assessment results [23]. The version 3.0 SOLRIS package includes a raster dataset (with all of the land cover designations), a vector land cover changes dataset, and a land cover class corrections dataset (including class updates, accuracy assessment results, and transformations) with a $15 \mathrm{~m}$ spatial resolution [24].

Simplified land cover classifications are used to reduce the quantity of different land covers to five categories (Forested, Wetland, Lakeside, Agricultural, and Urban) (Table 1). 'Wetland' refers to any surface where the water table is either seasonally or permanently at, near, or above the substrate surface [24]. Any weather station adjacent to a large water body is classified as "lakeside". Table 1 displays how the classifications are simplified into five main land cover categories. 
Table 1. The reclassification of all land covers into five manageable categories. Any station located in proximity to an open water land cover is reclassified as a lakeside station regardless of the dominant land cover within $100 \mathrm{~m}$.

\begin{tabular}{|c|c|c|c|c|}
\hline Agricultural & Urban & Lakeside & Forested & Wetlands \\
\hline Plantations-Tree Cultivated & Transportation & Open Water & Forest & Treed Swamp \\
\hline Hedge Rows & Built-Up Area-Pervious & & Coniferous Forest & Thicket Swamp \\
\hline Tilled & Built-Up Area-Impervious & & Mixed Forest & Marsh \\
\hline $\begin{array}{l}\text { Undifferentiated (orchards, } \\
\text { vineyards, perennial crops, } \\
\text { and idle land) }\end{array}$ & Extraction & & & \\
\hline
\end{tabular}

\subsection{Remote Sensing Data}

Imagery was collected from MODIS and Landsat TM sensors with different spatial and temporal resolutions, obtainable product levels, and processing requirements. Both remote sensing products use similar variables related to $\mathrm{T}_{\text {air }}$, such as albedo, LST, and normalized difference vegetation index (NDVI) [25].

\subsubsection{MODIS LST}

Selection of MODIS as coarse resolution sensors for the comparison is based on data availability, product accuracy, and an established foundation of land cover analysis reports. Consisting of two platforms launched in a similar time period as Landsat 7 ETM+ (although the Aqua platform was released in 2002), MODIS products can provide high accurate LST data, with spatial representativeness being a limiting factor [14,15,26-28].

MOD11A1 and MYD11A1 are level 3 LST products from the MODIS Terra and Aqua platforms on a $1200 \times 1200$ pixel grid, with an exact spatial resolution of $0.928 \times 0.928 \mathrm{~km}$ in the Sinusoidal projection. LST pixel values are generated using the split-window algorithm (SWA) with clear-sky conditions and are averaged in areas with overlapping pixels with overlapping areas of weight [29]. Its advertised one-day temporal resolution is optimistic based on the availability of clear-sky distribution. Since the thermal infrared (TIR) bands on the MODIS sensors are unable to penetrate clouds, any pixel experiencing cloudy interference must be skipped [30].

Both satellite platforms operate on a sun-synchronous orbit [15]. Based on the estimates provided by the NASA LaRC Satellite Overpass Predictor (https: / cloudsway2.larc. nasa.gov/cgi-bin/predict/predict.cgi, accessed in 30 August 2020), the overpass times at the selected location for the Terra platform range between 10:00 and 12:30 and 12:00 to 14:30 for Aqua in the local Eastern Standard Time.

\subsubsection{Landsat 7-Derived LST}

Landsat 7 ETM+ was the ideal choice for finer resolution LST data. It is a major leap forward from its predecessors, with multispectral spatial resolutions ranging from its $15 \mathrm{~m}$ panchromatic band to the $60 \mathrm{~m}$ TIR band [31]. Reference [1] presents an innovative method using the Statistical Mono-Window Algorithm (SMW) in Google Earth Engine to simplify the calculations needed to derive LST by reducing the amplitude of data required for time series analyses. Access to the algorithm is simply introduced through the use of the JavaScript function "require ( ... )", thus eliminating the necessity to download bulk quantities of data. To retain data consistency, no interpolation was performed following the failure of the Landsat 7 scan line corrector, resulting in pixilation loss.

To access LST, the surface reflectance is calculated from the radiative transfer for atmospheric data using the Landsat Ecosystem Disturbance Adaptive Processing System Algorithm [1]. A cloud mask is applied to eliminate interference. Data from the Advanced Spaceborne Thermal Emission and Reflection Radiometer Global Emissivity Dataset (ASTER) is spectrally adjusted and modified accounting for phenology and snow coverage using shortwave infrared Landsat data [32]. The SMW algorithm used within the [1] code presents two options for achieving LST, the direct application of instantaneous 
ASTER emissivity corrected values or the inclusion of NDVI-based corrections. With the latter option, the coarse TIR band can be resampled with an enhanced spatial resolution from NDVI and surface emissivity to generate LST [33]. For the purposes of understanding the influence which NDVI has upon LST, both methods are implemented.

\subsection{Analysis Methods}

The first step involves the data extraction from all meteorological stations collecting hourly data within the study area, from 1 January 2000 to 31 December 2019. From each station, all 16:00 data was used for comparison with the Landsat 7 ETM+-derived LST data. Since the time of the data acquired from both MODIS platforms ranges from 10:00 to 14:30, every hour's temperature recordings within the range are used, relative to its corresponding satellite. The daily mean and maximum $\mathrm{T}_{\text {air }}$ measurements are also incorporated due to the SWA processing techniques for acquiring LST. A $100 \mathrm{~m}$ buffer is implemented surrounding each weather station to determine the dominant land cover from SOLRIS data. All stations classified under each surface type are grouped together.

Based on the provided longitude and latitude data from each weather station, all MODIS (Terra and Aqua) and Landsat 7 LST data are extracted for the time series analysis. Among all the $\mathrm{T}_{\text {air }}$ and LST data extracted, only the data that exists when in situ measurements and remote sensing data were simultaneously collected are utilized for comparison. The quantity of $\mathrm{T}_{\text {air }}$ and LST observations pairs within each analysis is included in Tables 3-7.

To better compare the satellite-based LST and $\mathrm{T}_{\text {air }}$, each year is divided into two parts, representing the changing land surface distribution amongst seasons (summer and winter). Rather than utilizing the four traditional seasons, each year only uses two to describe the changing land surface characteristics due to the short spring and fall seasons. The warmer portion of the year, referred to as "summer" (days 100-290), ranges from mid-spring (April 9/10) to mid-autumn (October 16/17), and the colder portion (named "winter" in reference to days 1-99 and 291-366) indicates the rest of the year. The summer content is largely unaffected by snow or ice coverage and is representative of vegetation growth and increased solar radiation, as opposed to the winter.

Linear regression analyses are conducted based on geographical variables land cover type for summer and winter days and performed through $\mathrm{R}$. The results are compared using $\mathrm{R}^{2}$ values, root-mean square error (RMSE), bias, and the number of observations. All remote sensing data are acquired and processed in Google Earth Engine.

An additional comparison between satellites excludes $T_{\text {air }}$ measurements. Several large areas with land cover consistently within each category are selected and aggregated. Within each land cover designation, 70 points are randomly selected accessing the mean temperature within a $50 \mathrm{~m}$ homogenous buffer. The mean LST measurements from each category and platform are compared to determine the quantity and quality of the variations of data.

\section{Results}

As a result of the vastly different temporal resolutions amongst the remote sensing platforms, there is far less $\mathrm{T}_{\text {air }}$ data to compare with the Landsat 7 LST. The validity of all analyses is based on $p$-values and the $\mathrm{R}^{2}$ values, which measure the quantity of variance in the dependent variable explained through the independent variable [34]. All regression results from these analyses produced statistically significant $p$-values, with a few exceptions (all of which are related to the small quantity of LST data to compare with wetlands $\mathrm{T}_{\text {air }}$ measurements due to the limited quantity of stations on or near wetlands). In addition, the RMSE and bias were included to further understand the distribution of residuals and real values [25]. The bias refers to subtracting the LST by $\mathrm{T}_{\text {air, }}$ or in the Landsat $7 /$ MODIS comparison, MODIS LST minus Landsat 7 LST.

Table 2 summarizes the regression analysis results based on all pairs in winter days and summer days. In general, there are higher $R^{2}$ values in the winter days compared 
with the corresponding values in summer days, indicating a stronger relationship in all comparisons in winter than in the summer. The correlations are slightly higher between $\mathrm{T}_{\text {air }}$ and Terra LST than Aqua LST, although this difference is not significant at all. The slight difference in correlations during the different time is not significant, indicating the similar trend of different temperature measurements when compared with LST. LST from Terra with $\mathrm{T}_{\text {air }}$ recorded at 12:00 provides the strongest overall relationship with either of the MODIS missions, with an $\mathrm{R}^{2}$ value of 0.79 . The Landsat 7 NDVI-derived LST's relationship with $\mathrm{T}_{\text {air }}$ is a marginal improvement, with RMSE of 4.16 and an $\mathrm{R}^{2}$ value of 0.81 , slightly higher than ASTER-derived data. In contrast, the summer data in Table 2 correlations are far less robust. Comparisons with MODIS data have $\mathrm{R}^{2}$ values as high as 0.45 , while the Landsat 7 LST overall data comparison is slightly weaker, with $R^{2}$ values of 0.35 .

Amongst the two Landsat 7 LST datasets, the results are very similar. NDVI corrections produce marginally improved $R^{2}$ and RMSE values; however, the bias is weaker.

Table 2. The results from regression analyses for both MODIS Aqua and Terra and Landsat 7 for winter days (Days 1-99 and 291-366) and summer days (Days 100-290) of every year between 2000 and 2019. The $T_{\text {air }}$ relationships with the best $R^{2}$ results are included. All $p$-values are $<0.001$.

\begin{tabular}{|c|c|c|c|c|c|c|}
\hline \multirow[b]{2}{*}{ Regression Variables } & \multicolumn{3}{|c|}{ Winter Days } & \multicolumn{3}{|c|}{ Summer Days } \\
\hline & $\mathbf{R}^{2}$ & RMSE & Bias & $\mathbf{R}^{2}$ & RMSE & Bias \\
\hline 12:00 Air Temperature and Aqua LST & 0.74 & 4.64 & 3.17 & 0.38 & 5.28 & 6.08 \\
\hline 13:00 Air Temperature and Aqua LST & 0.75 & 4.61 & 2.58 & 0.38 & 5.29 & 5.49 \\
\hline 14:00 Air Temperature and Aqua LST & 0.75 & 4.57 & 2.22 & 0.38 & 5.26 & 5.12 \\
\hline Daily Mean Air Temperature and Aqua LST & 0.72 & 4.85 & 5.58 & 0.41 & 5.16 & 9.68 \\
\hline Daily Maximum Air Temperature and Aqua LST & 0.74 & 4.69 & 1.27 & 0.40 & 5.19 & 4.28 \\
\hline 10:00 Air Temperature and Terra LST & 0.78 & 4.38 & 3.60 & 0.44 & 4.68 & 6.14 \\
\hline 11:00 Air Temperature and Terra LST & 0.79 & 4.29 & 2.53 & 0.44 & 4.70 & 5.18 \\
\hline 12:00 Air Temperature and Terra LST & 0.79 & 4.27 & 1.74 & 0.43 & 4.71 & 4.45 \\
\hline Daily Mean Air Temperature and Terra LST & 0.76 & 4.54 & 4.14 & 0.45 & 4.64 & 8.17 \\
\hline Daily Maximum Air Temperature and Terra LST & 0.77 & 4.43 & -0.11 & 0.45 & 4.64 & 2.73 \\
\hline 16:00 Air Temperature and Landsat 7 NDVI LST & 0.81 & 4.16 & 2.48 & 0.35 & 6.14 & 5.28 \\
\hline 16:00 Air Temperature and Landsat 7 ASTER LST & 0.78 & 4.50 & 1.68 & 0.35 & 6.34 & 4.59 \\
\hline
\end{tabular}

Tables 3-7 list the $\mathrm{R}^{2}$ values, RMSE, and biases from regression analysis between LSTs and $T_{\text {air }}$ for stations located in five land cover types respectively, along with the number of pairs used in the analysis. The summer and winter analyses developed differing conclusions regarding the land cover in which strongest relationships between LST and $\mathrm{T}_{\text {air }}$ exist. In the summer, the wetland surfaces had the most robust correlations, with MODIS at $R^{2}$ values as high as 0.69 (Terra and the daily maximum $T_{\text {air }}$ ) and the smallest RMSE. Meanwhile, both Landsat 7 LST measurements failed to collect enough data from stations located near wetlands. With the other land covers, $\mathrm{R}^{2}$ and RMSE results between fine-resolution LST data and $\mathrm{T}_{\text {air }}$ were only slightly weaker than MODIS relationships with forested and lakeside stations compared to larger deviations with agriculture and urban.

With the winter comparisons, Landsat 7 LST showed stronger correlation with $\mathrm{T}_{\text {air }}$ than MODIS LSTs; however, they are only marginally better in agricultural and urban areas. Forested weather stations' data during the cold season exhibit the largest deviation in variance explained through Landsat 7 LST $\left(R^{2}\right.$ values of 0.67 without NDVI) over the highest MODIS $R^{2}$ values of 0.50 . All other land covers yield similar comparisons, with slight improvements when NDVI corrections are applied to calculate LST.

The number of observations with Landsat 7 is a continuous issue throughout the analysis. Wetlands results with Landsat 7 are insufficient throughout both seasons. Although conclusions can be drawn with forested land covers, the quantity of winter observations limits the validity. 
With the scaled LST analysis excluding $\mathrm{T}_{\text {air }}$, the relationships are marginally stronger with the MODIS Terra platform and Landsat 7 with NDVI across both seasons and every land cover. Much like the $\mathrm{T}_{\text {air }}$ comparisons, the winter has significantly stronger correlations, with the only exception being open water land covers.

Winter results in Tables 3-7 show that fine-resolution LST with NDVI corrections and coarse resolution data from MODIS Terra have the strongest relationship based on every conducted measurement. For summer results, Landsat 7 LST using NDVI has an improved relationship, with $R^{2}$ values ranging from 0.74 to 0.91 , with Terra. Relationships over water bodies provided the strongest summer $\mathrm{R}^{2}$ and RMSE ( 0.91 and 1.98 , respectively) results between Landsat 7 and the Terra sensor.

Table 3. Detailed results from regression analyses conducted using both MODIS satellites and Landsat 7 against air temperature based on agricultural in situ stations. All $p$-values are $<0.001$.

\begin{tabular}{|c|c|c|c|c|c|c|c|c|}
\hline \multirow[b]{2}{*}{ Regression Variables } & \multicolumn{4}{|c|}{ Summer Days } & \multicolumn{4}{|c|}{ Winter Days } \\
\hline & $\mathrm{R}^{2}$ & RMSE & Bias & $\mathbf{N}$ & $\mathbf{R}^{2}$ & RMSE & Bias & $\mathbf{N}$ \\
\hline 12:00 $\mathrm{T}_{\text {air }}$ and Aqua LST & 0.42 & 4.86 & 7.38 & 6741 & 0.80 & 4.56 & 3.30 & 2746 \\
\hline $13: 00 \mathrm{~T}_{\text {air }}$ and Aqua LST & 0.42 & 4.86 & 6.78 & 6738 & 0.80 & 4.51 & 2.68 & 2747 \\
\hline $14: 00 \mathrm{~T}_{\text {air }}$ and Aqua LST & 0.43 & 4.83 & 6.39 & 6741 & 0.80 & 4.47 & 2.30 & 2744 \\
\hline Daily Mean $\mathrm{T}_{\text {air }}$ and Aqua LST & 0.47 & 4.66 & 11.46 & 6782 & 0.78 & 4.67 & 5.92 & 2773 \\
\hline Daily Maximum $\mathrm{T}_{\text {air }}$ and Aqua LST & 0.45 & 4.73 & 5.68 & 6782 & 0.79 & 4.59 & 1.42 & 2773 \\
\hline 10:00 $\mathrm{T}_{\text {air }}$ and Terra LST & 0.50 & 4.14 & 7.41 & 7663 & 0.82 & 4.21 & 3.72 & 3425 \\
\hline 11:00 $\mathrm{T}_{\text {air }}$ and Terra LST & 0.49 & 4.19 & 6.38 & 7671 & 0.83 & 4.13 & 2.59 & 3433 \\
\hline 12:00 $\mathrm{T}_{\text {air }}$ and Terra LST & 0.48 & 4.22 & 5.60 & 7658 & 0.83 & 4.14 & 1.78 & 3446 \\
\hline Daily Mean $\mathrm{T}_{\text {air }}$ and Terra LST & 0.52 & 4.06 & 9.83 & 7713 & 0.81 & 4.33 & 4.38 & 3471 \\
\hline Daily Maximum $\mathrm{T}_{\text {air }}$ and Terra LST & 0.51 & 4.12 & 3.97 & 7713 & 0.81 & 4.37 & -0.09 & 3472 \\
\hline $16: 00 \mathrm{~T}_{\text {air }}$ and Landsat 7 NDVI LST & 0.37 & 5.90 & 6.90 & 193 & 0.85 & 3.77 & 2.65 & 96 \\
\hline 16:00 $\mathrm{T}_{\text {air }}$ and Landsat 7 ASTER LST & 0.36 & 6.29 & 6.03 & 232 & 0.82 & 4.29 & 1.88 & 130 \\
\hline
\end{tabular}

Table 4. Detailed results from regression analyses conducted using both MODIS satellites and Landsat 7 against air temperature based on urban in situ stations. All $p$-values are $<0.001$.

\begin{tabular}{|c|c|c|c|c|c|c|c|c|}
\hline \multirow[b]{2}{*}{ Regression Variables } & \multicolumn{4}{|c|}{ Summer Days } & \multicolumn{4}{|c|}{ Winter Days } \\
\hline & $\mathbf{R}^{2}$ & RMSE & Bias & $\mathbf{N}$ & $\mathbf{R}^{2}$ & RMSE & Bias & $\# \mathbf{N}$ \\
\hline $12: 00 \mathrm{~T}_{\text {air }}$ and Aqua LST & 0.53 & 4.27 & 5.50 & 11,738 & 0.79 & 4.11 & 3.46 & 5025 \\
\hline $13: 00 \mathrm{~T}_{\text {air }}$ and Aqua LST & 0.53 & 4.27 & 4.91 & 11,741 & 0.79 & 4.06 & 2.82 & 5042 \\
\hline $14: 00 \mathrm{~T}_{\text {air }}$ and Aqua LST & 0.54 & 4.24 & 4.52 & 11,733 & 0.80 & 4.00 & 2.47 & 5036 \\
\hline Daily Mean $\mathrm{T}_{\text {air }}$ and Aqua LST & 0.56 & 4.14 & 9.35 & 11,982 & 0.76 & 4.37 & 6.00 & 5166 \\
\hline Daily Maximum $\mathrm{T}_{\text {air }}$ and Aqua LST & 0.54 & 4.20 & 3.82 & 11,982 & 0.78 & 4.16 & 1.61 & 5166 \\
\hline 10:00 $\mathrm{T}_{\mathrm{air}}$ and Terra LST & 0.58 & 3.84 & 5.88 & 13,033 & 0.81 & 3.99 & 3.91 & 5945 \\
\hline 11:00 $\mathrm{T}_{\text {air }}$ and Terra LST & 0.58 & 3.83 & 4.84 & 13,058 & 0.82 & 3.89 & 2.78 & 5958 \\
\hline 12:00 $\mathrm{T}_{\text {air }}$ and Terra LST & 0.58 & 3.83 & 4.07 & 13,074 & 0.82 & 3.85 & 1.92 & 5952 \\
\hline Daily Mean $\mathrm{T}_{\text {air }}$ and Terra LST & 0.58 & 3.85 & 8.06 & 13,343 & 0.79 & 4.18 & 4.48 & 6126 \\
\hline Daily Maximum $\mathrm{T}_{\text {air }}$ and Terra LST & 0.59 & 3.82 & 2.49 & 13,343 & 0.81 & 3.99 & 0.15 & 6126 \\
\hline $16: 00 \mathrm{~T}_{\text {air }}$ and Landsat 7 NDVI LST & 0.46 & 5.23 & 5.81 & 469 & 0.84 & 3.79 & 3.10 & 188 \\
\hline 16:00 $\mathrm{T}_{\text {air }}$ and Landsat 7 ASTER LST & 0.44 & 5.64 & 5.03 & 569 & 0.81 & 4.17 & 2.37 & 277 \\
\hline
\end{tabular}


Table 5. Detailed results from regression analyses conducted using both MODIS satellites and Landsat 7 against air temperature based on lakeside in situ stations. All $p$-values are $<0.001$.

\begin{tabular}{|c|c|c|c|c|c|c|c|c|}
\hline \multirow[b]{2}{*}{ Regression Variables } & \multicolumn{4}{|c|}{ Summer Days } & \multicolumn{4}{|c|}{ Winter Days } \\
\hline & $\mathbf{R}^{2}$ & RMSE & Bias & $\mathbf{N}$ & $\mathbf{R}^{2}$ & RMSE & Bias & $\mathbf{N}$ \\
\hline $12: 00 \mathrm{~T}_{\text {air }}$ and Aqua LST & 0.39 & 4.91 & 8.51 & 4789 & 0.68 & 5.47 & 3.39 & 1964 \\
\hline $13: 00 \mathrm{~T}_{\text {air }}$ and Aqua LST & 0.39 & 4.92 & 8.02 & 4797 & 0.68 & 5.48 & 2.94 & 1966 \\
\hline 14:00 $\mathrm{T}_{\text {air }}$ and Aqua LST & 0.39 & 4.92 & 7.60 & 4792 & 0.68 & 5.49 & 2.59 & 1962 \\
\hline Daily Mean $\mathrm{T}_{\text {air }}$ and Aqua LST & 0.32 & 5.18 & 10.38 & 4831 & 0.64 & 5.77 & 4.71 & 1989 \\
\hline Daily Maximum $\mathrm{T}_{\text {air }}$ and Aqua LST & 0.39 & 4.89 & 6.16 & 4831 & 0.67 & 5.56 & 1.16 & 1989 \\
\hline 10:00 $\mathrm{T}_{\text {air }}$ and Terra LST & 0.45 & 4.33 & 7.69 & 5511 & 0.72 & 5.01 & 3.27 & 2474 \\
\hline $11: 00 \mathrm{~T}_{\text {air }}$ and Terra LST & 0.44 & 4.34 & 7.06 & 5517 & 0.73 & 4.94 & 2.51 & 2479 \\
\hline $12: 00 \mathrm{~T}_{\text {air }}$ and Terra LST & 0.43 & 4.37 & 6.52 & 5513 & 0.73 & 4.93 & 1.92 & 2477 \\
\hline Daily Mean $\mathrm{T}_{\text {air }}$ and Terra LST & 0.38 & 4.57 & 8.38 & 5572 & 0.69 & 5.22 & 3.25 & 2504 \\
\hline Daily Maximum $\mathrm{T}_{\text {air }}$ and Terra LST & 0.44 & 4.35 & 4.18 & 5572 & 0.72 & 5.07 & -0.26 & 2504 \\
\hline 16:00 $\mathrm{T}_{\text {air }}$ and Landsat 7 NDVI LST & 0.32 & 5.24 & 6.19 & 204 & 0.75 & 4.73 & 1.64 & 90 \\
\hline 16:00 $\mathrm{T}_{\text {air }}$ and Landsat 7 ASTER LST & 0.37 & 5.30 & 5.55 & 256 & 0.74 & 4.94 & 0.38 & 130 \\
\hline
\end{tabular}

Table 6. Detailed results from regression analyses conducted using both MODIS satellites and Landsat 7 against air temperature based on forested in situ stations. All $p$-values are $<0.001$.

\begin{tabular}{|c|c|c|c|c|c|c|c|c|}
\hline \multirow[b]{2}{*}{ Regression Variables } & \multicolumn{4}{|c|}{ Summer Days } & \multicolumn{4}{|c|}{ Winter Days } \\
\hline & $\mathbf{R}^{2}$ & RMSE & Bias & $\mathbf{N}$ & $\mathbf{R}^{2}$ & RMSE & Bias & $\mathbf{N}$ \\
\hline $12: 00 \mathrm{~T}_{\text {air }}$ and Aqua LST & 0.53 & 3.87 & -3.72 & 1695 & 0.48 & 3.24 & 0.87 & 883 \\
\hline $13: 00 \mathrm{~T}_{\text {air }}$ and Aqua LST & 0.53 & 3.90 & -4.24 & 1698 & 0.48 & 3.24 & 0.37 & 882 \\
\hline $14: 00 \mathrm{~T}_{\text {air }}$ and Aqua LST & 0.52 & 3.93 & -4.47 & 1698 & 0.47 & 3.27 & 0.10 & 884 \\
\hline Daily Mean $\mathrm{T}_{\text {air }}$ and Aqua LST & 0.51 & 3.97 & 0.77 & 1708 & 0.47 & 3.30 & 3.99 & 891 \\
\hline Daily Maximum $\mathrm{T}_{\text {air }}$ and Aqua LST & 0.50 & 3.99 & -5.21 & 1708 & 0.46 & 3.31 & -0.63 & 891 \\
\hline 10:00 $\mathrm{T}_{\mathrm{air}}$ and Terra LST & 0.53 & 3.87 & -2.93 & 1903 & 0.49 & 3.31 & 2.29 & 977 \\
\hline 11:00 $\mathrm{T}_{\text {air }}$ and Terra LST & 0.52 & 3.93 & -3.89 & 1908 & 0.49 & 3.29 & 1.19 & 980 \\
\hline $12: 00 \mathrm{~T}_{\text {air }}$ and Terra LST & 0.52 & 3.93 & -4.56 & 1908 & 0.50 & 3.30 & 0.47 & 980 \\
\hline Daily Mean $\mathrm{T}_{\text {air }}$ and Terra LST & 0.50 & 4.01 & 0.07 & 1920 & 0.49 & 3.38 & 3.66 & 990 \\
\hline Daily Maximum $\mathrm{T}_{\text {air }}$ and Terra LST & 0.49 & 4.03 & -5.96 & 1920 & 0.48 & 3.39 & -0.97 & 990 \\
\hline 16:00 $\mathrm{T}_{\mathrm{air}}$ and Landsat 7 NDVI LST & 0.47 & 4.82 & -4.79 & 74 & 0.59 & 3.60 & 0.33 & 23 \\
\hline 16:00 $\mathrm{T}_{\text {air }}$ and Landsat 7 ASTER LST & 0.38 & 5.40 & -5.17 & 85 & 0.67 & 3.77 & 0.38 & 34 \\
\hline
\end{tabular}

Table 7. Detailed results from regression analyses conducted using both MODIS satellites and Landsat 7 against air temperature based on wetland in situ stations. All MODIS $p$-values are $<0.001$ (with Landsat 7 , it is NA).

\begin{tabular}{|c|c|c|c|c|c|c|c|c|}
\hline \multirow[b]{2}{*}{ Regression Variables } & \multicolumn{3}{|c|}{ Summer (Days 100-290) } & \multicolumn{5}{|c|}{ Winter (Days 1-99 and 291-366) } \\
\hline & $\mathbf{R}^{2}$ & RMSE & Bias & $\mathbf{N}$ & $\mathbf{R}^{2}$ & RMSE & Bias & $\mathbf{N}$ \\
\hline $12: 00 \mathrm{~T}_{\text {air }}$ and Aqua LST & 0.63 & 3.99 & 8.81 & 1041 & 0.88 & 3.45 & 2.78 & 458 \\
\hline 13:00 $\mathrm{T}_{\text {air }}$ and Aqua LST & 0.64 & 3.96 & 8.15 & 1039 & 0.88 & 3.43 & 2.00 & 458 \\
\hline $14: 00 \mathrm{~T}_{\text {air }}$ and Aqua LST & 0.64 & 3.96 & 7.72 & 1028 & 0.88 & 3.42 & 1.52 & 459 \\
\hline Daily Mean $\mathrm{T}_{\text {air }}$ and Aqua LST & 0.59 & 4.22 & 13.26 & 1046 & 0.85 & 3.94 & 5.58 & 461 \\
\hline Daily Maximum $\mathrm{T}_{\text {air }}$ and Aqua LST & 0.65 & 3.93 & 7.16 & 1046 & 0.87 & 3.70 & 0.76 & 461 \\
\hline 10:00 $\mathrm{T}_{\text {air }}$ and Terra LST & 0.68 & 3.39 & 8.15 & 1225 & 0.91 & 3.19 & 3.41 & 621 \\
\hline $11: 00 \mathrm{~T}_{\text {air }}$ and Terra LST & 0.68 & 3.37 & 7.00 & 1231 & 0.92 & 3.00 & 2.12 & 620 \\
\hline $12: 00 \mathrm{~T}_{\text {air }}$ and Terra LST & 0.68 & 3.38 & 6.15 & 1228 & 0.92 & 3.01 & 1.14 & 622 \\
\hline Daily Mean $\mathrm{T}_{\text {air }}$ and Terra LST & 0.63 & 3.64 & 10.69 & 1236 & 0.89 & 3.38 & 3.70 & 625 \\
\hline Daily Maximum $\mathrm{T}_{\text {air }}$ and Terra LST & 0.69 & 3.36 & 4.61 & 1236 & 0.89 & 3.41 & -0.78 & 625 \\
\hline 16:00 $\mathrm{T}_{\text {air }}$ and Landsat 7 NDVI LST & NA & NA & 5.72 & 1 & NA & NA & -0.87 & 2 \\
\hline 16:00 $\mathrm{T}_{\text {air }}$ and Landsat 7 ASTER LST & NA & NA & 5.46 & 1 & 0.9721 & 1.47 & 0.98 & 5 \\
\hline
\end{tabular}

A visual analysis of the plots for individual weather stations was necessary to ensure that the temperature variations and patterns throughout each season in each year are followed closely. Although some stations have far more data than others, certain parameters are required to complete a thorough visual examination. $\mathrm{T}_{\text {air }}$ station dates which contain data recorded from both remote sensing platforms are used for the analysis. Figure 2 displays patterns that Landsat 7 (with NDVI corrections) LST data has with MODIS Aqua LST and the daily mean $\mathrm{T}_{\text {air }}$ recordings during the summer, and Figure 3 has a similar 
comparison except with MODIS Terra LST during the winter. Although the satelliteproduced LST data differs from the ground $\mathrm{T}_{\text {air }}$ data, winter patterns appear more aligned. Comparing the scatterplots in Figures 2 and 3, it is also clear that the summer LST has more mismatching between coarse-resolution MODIS and fine-resolution Landsat LSTs than the winter LSTs for both stations, indicating that the winter's ability to smooth heterogenous surfaces presented stronger relationships with both LST and $\mathrm{T}_{\text {air }}$ over land cover.
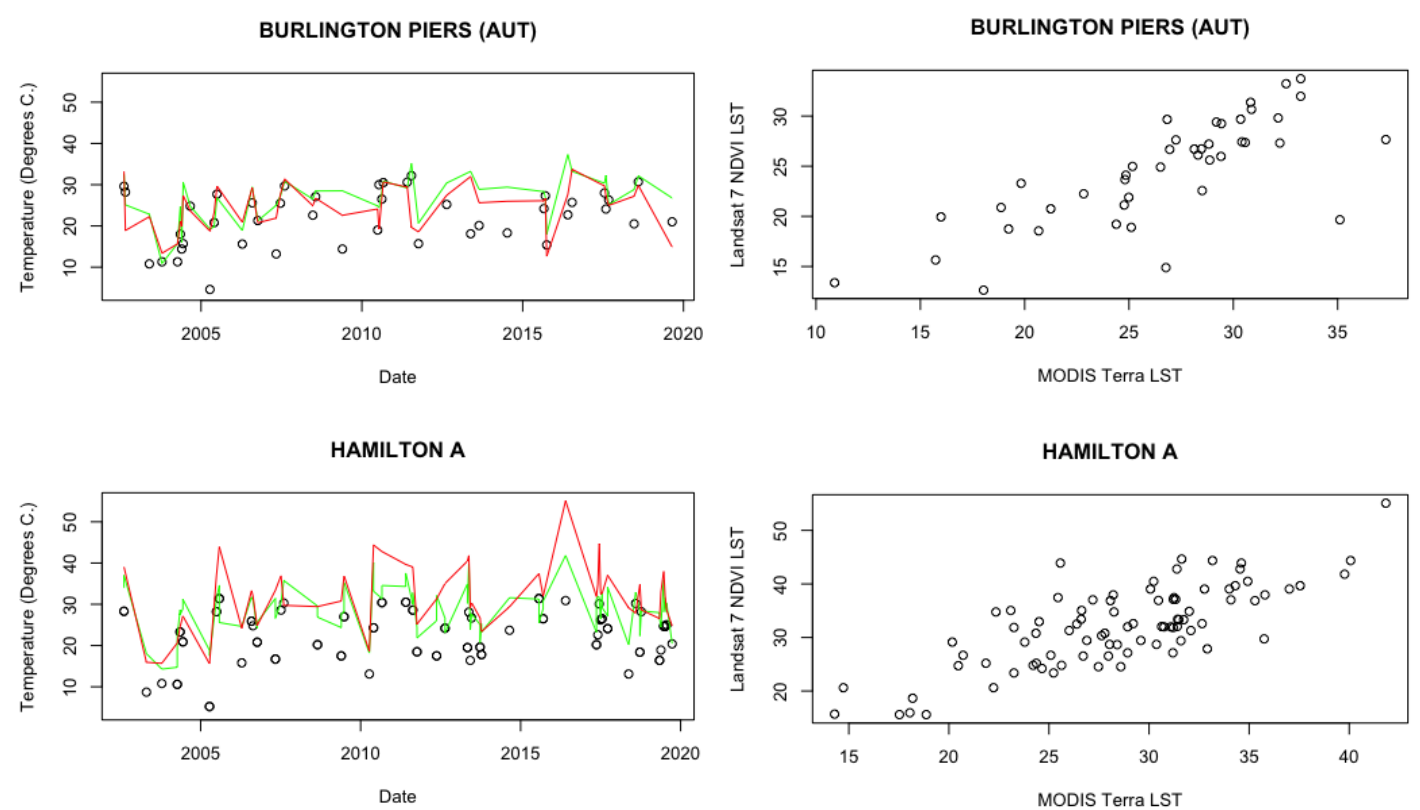

Figure 2. The time series (left) and scatterplots (right) of the Landsat 7 NDVI-derived LST and MODIS Aqua LST along with average air temperature at the stations with the most data points during the summer. The green line represents MODIS LST, the red line represents Landsat 7 LST, and the black points represent average air temperature observations. Burlington Piers is a lakeside station and Hamilton A is within agricultural land.
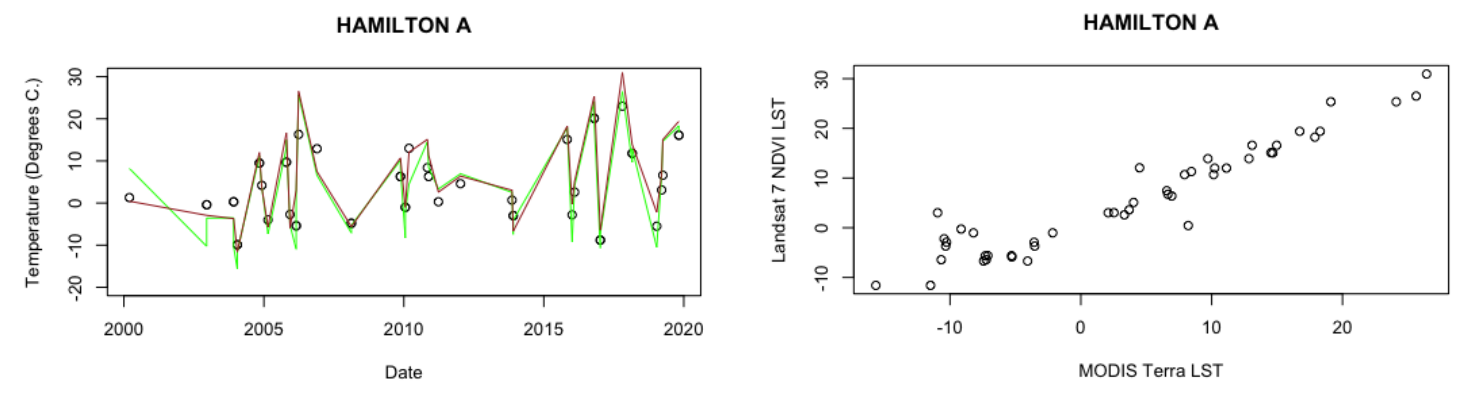

ST CATHARINES A

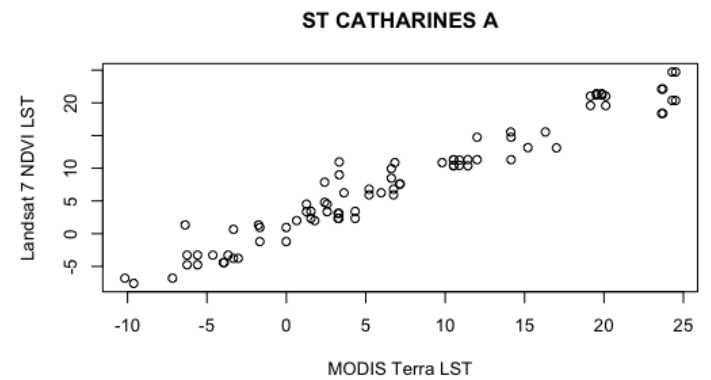

Figure 3. The time series (left) and scatterplots (right) of the Landsat 7 NDVI-derived LST and MODIS Terra LST along with average air temperature at the stations with the most data points during the winter. The green line represents MODIS LST, the red line represents Landsat 7 LST, and the black points represent average air temperature observations. St Catherines A is an urban station setting and Hamilton $\mathrm{A}$ is surrounded with agricultural land. 


\section{Discussion}

A major obstacle confronted in this analysis relates to the vastly different quantities of imagery available from each satellite platform. The 16-day revisit cycle for the Landsat 7 satellite limits the availability of data to compare and analyze with MODIS and $\mathrm{T}_{\text {air }}$. Both MODIS platforms calculate the LST based on clear-sky pixel coverage, masking clouds with the cloud mask algorithm [29]. The strongest correlations between MODIS and specific $T_{\text {air }}$ hours varies based on the range of overpass times and SWA methods used to achieve LST. With Landsat 7-derived LST, only 479 observations are possible (provided every overpass occurs during a clear sky) at each location throughout the provided time frame compared to the near daily results optimistically attainable from MODIS.

\subsection{Impact of Seasonality}

The results based on time of year remain consistent with previous research comparing MODIS results with $\mathrm{T}_{\mathrm{air}}$. The authors of [16] noted the much stronger relationship that MODIS LST has in the winter (daytime and nighttime) when compared with the summer daytime (the nighttime results were stronger due to lacking a solar radiation variable), with fluctuations based on ecological context. Other researchers [21] concluded that the relationships between surface temperature and air temperature were the strongest during late summer and autumn, and the weakest during winter and early spring in complex mountainous regions of Nevada. Stronger relationships between LST and $\mathrm{T}_{\text {air }}$ are found in winter than summer with both scales in this study. Extensive snow and ice cover in the winter can cause more homogeneity of land cover, except forest land. Surface conditions, changes to the soil moisture content, and heterogeneity of the surrounding land covers can play a major role in determining the variations in the summer days.

Winter seasonal energy exchanges heavily affect the comparisons in this study. The albedo consistency varies based on low-temperature snow coverage over agriculture, grassland, near-surface shrubbery, and diversified canopy cover, with heterogenous types of forest life [35]. The impact is limited to the spatial resolution each sensor possesses and the ecosystems surrounding the study site. In addition, due to the time frame of the winter analysis (mid-October to mid-April), discrepancies can occur due to the varying degrees of snow coverage throughout the time interval. A temperature bias happens as the year progresses from the winter solstice, resulting in stronger solar radiation [36]. The necessity to encompass the entire period of each year where snow cover is possible enhances the ability to identify the true relationship LST has with $\mathrm{T}_{\text {air }}$, regardless of circumstances.

Overall, the finer scale LST products with NDVI corrections retained the strongest relationships with $\mathrm{T}_{\text {air }}$. With an $\mathrm{R}^{2}$ value of 0.81 (slightly higher than with coarse sensors) and RMSE of 4.16 (slightly lower than with coarse sensors), the winter's ability to homogenize the surrounding environment increases the reliability of surface temperature to determine near-surface temperatures. The relationship difference between coarse- and fine-resolution sensors is minor, with the exception of in situ stations surrounded by forested surfaces. Finer resolution LST and $T_{\text {air }}$ have $R^{2}$ values between 0.60 and 0.67 , compared to 0.50 with coarse-resolution LST.

The summer comparisons lead to alternative results with each land cover and scale. Surface temperatures are high with non-evaporating surfaces and lower with water bodies due to the radiant reflection. The reflected solar radiation on the impervious pixels can strongly impact the LST, especially at a finer scale. Vegetated covers also have low radiant temperature as a result of a reduction in heat stored in the soil from transpiration [37]. Overall, coarse-resolution LST data possess the strongest $\mathrm{R}^{2}$ and RMSE results, especially with the MODIS Terra platform. Agricultural and urban stations have the largest difference in relationship between coarse and fine resolutions, while lakeside, forested stations displayed minor improvements.

The diversity of temperatures across each land cover poses strong catalysts for how the remote sensing-derived LST relates to $T_{\text {air }}$, depending on scale. Each biome maintains its own unique set of physical, climatological, botanical, and animal habitat characteristics, 
which cause variances that are not expressed through simple temperature observations and predictions [16]. The diversity of variables within dense and sparse vegetation during the growing season affect the temperature on the ground and in the air above it. Comparing the coarse spatial resolution of MODIS to the much finer Landsat 7 data, the additional environmental factors can cause fluctuations, especially with agriculture and urban surfaces.

\subsection{Land Cover Impact}

The impact of land cover on land surface temperature has been widely recognized [12,37-40]. Different land cover types have different degrees of absorption of solar radiation, evaporation rate, heat storage, etc., and thus impact LST. Variations dependent on land cover type imply discrepancies based on vegetation cover, impervious surface distribution, and soil type. Bare lands absorb lower amounts of heat and reflect high radiation, leading to an increase in LST, while vegetative lands decrease LST. Areas with a lower surface albedo are more likely to result in a greater overestimation of daytime temperature in satellite images than areas with a higher surface albedo [28]. This is reflected in the weaker relationship at lakeside stations with larger RMSE results.

The phenology of a land cover can also have a major impact upon the temperature variations. For example, summer results in vegetated areas with increased canopy coverage provided stronger results with Landsat 7.

MODIS has advantages over finer spatial resolution sensors as it subsumes the detail throughout heterogenous urban and vegetated areas across broad geographical extents [12]. The precision useful with Landsat 7 LST analyses in the summer serves as a disadvantage when compared with in situ observations due to the increased likelihood of variables affecting $\mathrm{T}_{\text {air }}$ outside of the $30 \mathrm{~m}$ resolution pixels. For example, the RMSE values in Tables 3-7 and the Figure 2 patterns display how MODIS sensors have improved abilities for determining LST more closely aligned with $\mathrm{T}_{\text {air. }}$. Opposing results occur throughout the homogenously transformed surfaces during the winter season, with finer spatial resolutions yielding superior results expressed through $R^{2}$ and RMSE values.

Defining an exact location within pixels of either $1 \mathrm{~km}$ or $30 \mathrm{~m}$ spatial resolutions challenges the ability to acquire specified temperatures for that location. Although this issue exists with each land cover classification, the lakeside stations are the most problematic. Its issues are reduced in the winter, with snow cover affecting the spectral reflectance over water in a similar manner to land; however, complications are exposed in the summer time frame. In addition to the provided coordinates for each station not being detailed enough to have their locations precisely georeferenced, the proximity to the large Ontario Lake water body and proportion of land surfaces incorporated into the pixels affects the classification with MODIS calculations more than Landsat 7 . The open space over water bodies may also increase humidity- and wind-related elements, which affect $\mathrm{T}_{\text {air }}$ observations.

The forested in situ station's $\mathrm{T}_{\text {air }}$ relationship with coarse-resolution LST revealed the only instance where summer produced a stronger seasonal relationship. Due to the dense flora, the Canadian winter is unable to completely homogenize the forest environment. The canopy density produces low $\mathrm{R}^{2}$ values in the winter, which finer resolutions can marginally improve upon. Considering the strong results in the LST regression analysis based on scale, forested land covers inhabit variables, relevant to vegetation density and height, affecting air, which snow coverage fails to smooth at coarse resolutions.

The linear regression analyses between LST scales produced robust results, especially over forested and wetland pixels (compared with the $\mathrm{T}_{\text {air }}$ analyses which lacked sufficient data). In contrast to the limited number of observations at each weather station for comparisons with Landsat, Terra data produced far more results with superior variance and reliability in each regression analysis. The application of 70 randomly selected points for scaled LST comparisons allowed for more complete representations with land covers where in situ stations were seldomly placed. The summer comparison between Landsat 7 (with NDVI) and Terra delivered the strongest $\mathrm{R}^{2}$ and RMSE results, especially over water (due to its homogeneity) and forests. 
In the winter, the factors which affect the variance in summer LST, such as solar radiation, vegetation growth, surface roughness, and albedo, are reduced. Water is the land cover with the most variation and highest bias amongst the two platforms, with vastly different spatial resolutions (which contrasts summer results). The stronger relationship within water pixels in the summer is due to homogeneity with both fine and coarse spatial resolutions. Winter provides more variance with LST at a coarser scale.

\subsection{ASTER-Derived Emissivity Values vs. NDVI-Corrected Values}

The minor differentiation amongst the two methods of deriving LST from Landsat 7 imagery is definitive for this region. The only category in which NDVI-corrected values are not superior is around lakeside and forested in situ stations. NDVI LST data have a significantly stronger relationship with forested $\mathrm{T}_{\text {air }}$ in the summer. In contrast, ASTER LST values had an $\mathrm{R}^{2}$ improvement of 0.0732 in the winter. The only other instance is with lakeside stations during the summer. Otherwise, NDVI-corrected LST maintains a dominance. NDVI plays a stronger role with summer data due to the influx of vegetation across each land cover. In the winter, even with snow coverage and a major reduction of vegetation life, the results continue to reveal the necessity for NDVI corrections on the ASTER emissivity values.

\section{Conclusions}

This study evaluates the correlations between LST products from different MODIS platforms, Landsat 7 , and ground $\mathrm{T}_{\text {air }}$ measurements, and analyzes the impact of seasonality and land cover on the consistency of these relationships at a local scale. It was found that MODIS LST from Terra had stronger relationships with Landsat 7 LST than those from Aqua. $\mathrm{T}_{\text {air }}$ at the satellite over passing time does not show significantly different correlations from other $\mathrm{T}_{\text {air }}$ measurements. When compared to $\mathrm{T}_{\text {air }}$ measurements from calendar days 100 to 290, success with coarse-resolution LST products is reflective of previous research. MODIS imagery maintained overall $\mathrm{R}^{2}$ values between 0.41 and 0.45 , while Landsat 7 results were 0.35 with a weaker RMSE. For the remainder of the year, Landsat 7 is more highly correlated with overall $R^{2}$ value as high as 0.81 , while MODIS data is between 0.71 and 0.79 with similar RMSE.

Individual land covers produce much more varied results based on phenology, albedo, and moisture content on the heterogenous land surfaces during the summer. As a result, the summer conditions for a finer resolution satellite do not account for the greater variety of variables present in heterogenous surfaces. The differences in variances explained through coarse- and fine-resolution satellite imagery with $\mathrm{T}_{\text {air }}$ over lakeside and forested stations are marginally smaller $\left(\mathrm{R}^{2}\right.$ difference within 0.08$)$ compared to agriculture and urban surfaces. In addition, coarse-resolution LST explains more variance in $\mathrm{T}_{\text {air }}$ at forested locations during summer due to the winter's inability to homogenize the landscape due to dense flora content.

When comparisons based on the surrounding land covers for each in situ observation were conducted, Landsat 7-derived LST concluded with $\mathrm{R}^{2}$ values between 0.03 and 0.15 lower than MODIS in summer. Results with agricultural and urban in situ stations provided the most variations between air measurements and different LST scales. This emphasizes the disadvantage for using satellites with a finer spatial resolution during the summer due to a greater availability of heterogenous factors over sparse vegetation and low-density impervious spaces. Further assessment is needed on the atmospheric variability in a variety of environments based on the radiation, atmospheric contents, and surface biomass factors.

The availability of weather stations in or near wetlands was a limitation in the LST comparisons made with $\mathrm{T}_{\text {air }}$. For Landsat 7 data, 1 to 5 observations are entirely insufficient to make a distinction on its accuracy. Future exploration of the relationship with $\mathrm{T}_{\text {air }}$ stations may provide greater insight on the correlation with fine-resolution LST located at wetlands. 


\begin{abstract}
Author Contributions: Conceptualization, D.C., M.B.; methodology M.B., D.C.; software, M.B., D.C.; Data, M.B.; writing, M.B., D.C.; supervision, D.C. Both authors have read and agreed to the published version of the manuscript.
\end{abstract}

Funding: This research was supported by a National Science and Engineering Research Council (NSERC) Discovery Grant and Queen's Graduate Scholarship.

Institutional Review Board Statement: Not Applicable.

Informed Consent Statement: Not applicable.

Conflicts of Interest: The authors declare no conflict of interest.

\title{
References
}

1. Ermida, S.L.; Soares, P.; Mantas, V.; Gottsche, F.-M.; Trigo, I.F. Google Earth Engine Open-Source Code for Land Surface Temperature Estimation from the Landsat Series. J. Remote Sens. 2020, 12, 1471. [CrossRef]

2. de Affonseca, M.S.; Alves, R.N.; Junior, J.T.; de Almeida, C.E. The influence of urbanization on natural radiation levels in anomalous areas. J. Environ. Radioact. 2002, 63, 65-75. [CrossRef]

3. Chen, Y.-C.; Chiu, H.-W.; Su, Y.-F.; Wu, Y.-C.; Cheng, K.-S. Does urbanization increase diurnal land surface temperature variation? Evidence and implications. Landsc. Urban Plan. 2017, 157, 247-258. [CrossRef]

4. Streutker, D.R. Satellite-measured growth of the urban heat island of Houston, Texas. Remote Sens. Environ. 2003, 85, 282-289. [CrossRef]

5. Yang, Q.; Huang, X.; Tang, Q. The footprint of urban heat island effect in 302 Chinese cities: Temporal trends and associated factors. Sci. Total Environ. 2019, 655, 652-662. [CrossRef]

6. Zhou, D.; Zhao, S.; Zhang, L.; Sun, G.; Liu, Y. The footprint of urban heat island effect in China. Sci. Rep. 2015, 5, 1-11. [CrossRef]

7. Stewart, I.D.; Oke, T.R. Local Climate Zones for Urban Temperature Studies. Bull. Am. Meteorol. Soc. 2012, 93, 1879-1900. [CrossRef]

8. Almazroui, M.; Islam, M.N.; Jones, P.D. Urbanization effects on the air temperature rise in Saudi Arabia. Clim. Chang. 2013, 120, 109-122. [CrossRef]

9. Yang, Y.-J.; Wu, B.-W.; Shi, C.; Zhang, J.-H.; Li, Y.-B.; Tang, W.-A.; Wen, H.-Y.; Zhang, H.-Q.; Shi, T. Impacts of Urbanization and Station-relocation on Surface Air Temperature Series in Anhui Province, China. Pure Appl. Geophys. 2013, 170, 1969-1983. [CrossRef]

10. Kuenzer, C.; Klein, I.; Ullmann, T.; Georgiou, E.F.; Baumhauer, R.; Dech, S. Remote Sensing of River Delta Inundation: Exploiting the Potential of Coarse Spatial Resolution, Temporally-Dense MODIS Time Series. Remote Sens. 2015, 7, 8516-8542. [CrossRef]

11. Muad, A.M.; Foody, G.M. Super-resolution mapping of lakes from imagery with a coarse spatial and fine temporal resolution. Int. J. Appl. Earth Obs. Geoinf. 2012, 15, 79-91. [CrossRef]

12. Walker, J.J.; de Beurs, K.M.; Henebry, G.M. Land surface phenology along urban to rural gradients in the U.S. Great Plains. Remote Sens. Environ. 2015, 165, 42-52. [CrossRef]

13. Kempeneers, P.; Sedano, F.; Seebach, L.; Strobl, P.; San-Miguel-Ayanz, J. Data Fusion of Different Spatial Resolution Remote Sensing Images Applied to Forest-Type Mapping. IEEE Trans. Geosci. Remote Sens. 2011, 49, 4977-4986. [CrossRef]

14. Mildrexler, D.J.; Zhao, M.; Running, S.W. A global comparison between station air temperatures and MODIS land surface temperatures reveals the cooling role of forests. J. Geophys. Res. Biogeosciences 2011, 116, 1-15. [CrossRef]

15. Urban, M.; Eberle, J.; Hüttich, C.; Schmullius, C.; Herold, M. Comparison of Satellite-Derived Land Surface Temperature and Air Temperature from Meteorological Stations on the Pan-Arctic Scale. Remote Sens. 2013, 5, 2348-2367. [CrossRef]

16. Zhang, P.; Bounoua, L.; Imhoff, M.L.; Wolfe, R.E.; Thome, K. Comparison of MODIS Land Surface Temperature and Air Temperature over the Continental USA Meteorological Stations. Can. J. Remote Sens. 2014, 40, 110-122. [CrossRef]

17. Coll, C.; Caselles, V.; Galve, J.M.; Valor, E.; Niclos, R.; Sanchez, J.M.; Rivas, R. Ground measurements for the validation of land surface temperatures derived from AATSR and MODIS data. Remote Sens. Environ. 2005, 97, 288-300. [CrossRef]

18. Duan, S.-B.; Li, Z.-L.; Cheng, J.; Leng, P. Cross-satellite comparison of operational land surface temperature products derived from MODIS and ASTER data over bare soil surfaces. ISPRS J. Photogramm. Remote Sens. 2017, 126, 1-10. [CrossRef]

19. Ouyang, X.; Chen, D.; Feng, Y.; Lei, Y. Comparison of seasonal surface temperature trend, spatial variability, and elevation dependency from satellite-derived products and numerical simulations over the Tibetan Plateau from 2003 to 2011 . Int. J. Remote Sens. 2019, 40, 1844-1857. [CrossRef]

20. Parida, B.R.; Oinam, B.; Patel, N.R.; Sharma, N.; Kandwal, R.; Hazarika, M.K. Land surface temperature variation in relation to vegetation type using MODIS satellite data in Gujarat state of India. Int. J. Remote Sens. 2008, 29, 4219-4235. [CrossRef]

21. Mutiibwa, D.; Strachan, S.; Albright, T. Land Surface Temperature and Surface Air Temperature in Complex Terrain. IEEE J. Sel. Top. Appl. Earth Obs. Remote Sens. 2015, 8, 4762-4774. [CrossRef]

22. Kawashima, S.; Ishida, T.; Minomura, M.; Miwa, T. Relations between Surface Temperature and Air Temperature on a Local Scale during Winter Nights. J. Appl. Meteorol. Climatol. 2000, 39, 1570-1579. [CrossRef] 
23. Sampson, P. SOLRIS Accuracy Assessment Report 1: Golden Horseshoe Area (SOLRIS study area A) (Accuracy Assessment 1) Version 2.0. Minist. Nat. Resour. 2007, 53. Available online: https://maps.niagararegion.ca/Metadata/md/DocumentUpload/20 08-01-02\%2017-59-57.pdf (accessed on 20 July 2020).

24. Science and Research Branch of the Ministry of Natural Resources and Forestry. Southern Ontario Land Resource Information System (SOLRIS) Version 3.0: Data Specifications Minist. Nat. Resour.. 2019. Available online: https:/ /www.sdc.gov.on.ca/sites/ MNRF-PublicDocs/EN/CMID/SOLRIS\%20v3.0\%20-\%20Data\%20Specifications.pdf (accessed on 20 July 2020).

25. Cristobal, J.; Ninyerola, M.; Pons, X. Modeling air temperature through a combination of remote sensing and GIS data. J. Geophys. Res. 2008, 113. [CrossRef]

26. Bosilovich, M.G. A comparison of MODIS land surface temperature with in situ observations—Bosilovich—2006-Geophysical Research Letters-Wiley Online Library. Geophys. Res. Lett. 2006, 33. [CrossRef]

27. Coll, C.; Wan, Z.; Galve, J.M. Temperature-based and radiance-based validations of the V5 MODIS land surface temperature product. J. Geophys. Res. Atmos. 2009, 114. [CrossRef]

28. El Kenawy, A.M.; Hereher, M.E.; Robaa, S.M. An Assessment of the Accuracy of MODIS Land Surface Temperature over Egypt Using Ground-Based Measurements. J. Remote Sens. 2019, 11, 2369. [CrossRef]

29. Wan, Z. Collection-6 MODIS Land Surface Temperature Products Users' Guide. University of California. 2013. Available online: https:/ /lpdaac.usgs.gov/documents/118/MOD11_User_Guide_V6.pdf (accessed on 17 June 2020).

30. Wan, Z.; Zhang, Y.; Zhang, Q.; Li, Z.-L. Quality assessment and validation of the MODIS global land surface temperature. Int. J. Remote Sens. 2004, 25, 261-274. [CrossRef]

31. Yang, L.; Huang, C.; Homer, C.G.; Wylie, B.K.; Coan, M.J. An approach for mapping large-area impervious surfaces: Synergistic use of Landsat-7 ETM+ and high spatial resolution imagery. Can. J. Remote Sens. 2003, 29, 230-240. [CrossRef]

32. Malakar, N.K.; Hulley, G.C.; Hook, S.J.; Laraby, K.; Cook, M.; Schott, J.R. An Operational Land Surface Temperature Product for Landsat Thermal Data: Methodology and Validation. IEEE Trans. Geosci. Remote Sens. 2018, 56, 5717-5735. [CrossRef]

33. Rodriguez-Galiano, V.; Pardo-Iguzquiza, E.; Sanchez-Castillo, M.; Chica-Olmo, M.; Chica-Rivas, M. Downscaling Landsat 7 ETM+ thermal imagery using land surface temperature and NDVI images. Int. J. Appl. Earth Obs. Geoinf. 2012, 18, 515-527. [CrossRef]

34. Zhang, Y.; Balzter, H.; Wu, X. Spatial-temporal patterns of urban anthropogenic heat discharge in Fuzhou, China, observed from sensible heat flux using Landsat TM/ETM+ data. Int. J. Remote Sens. 2012, 34, 1459-1477. [CrossRef]

35. Essery, R. Large-scale simulations of snow albedo masking by forests. Geophys. Res. Lett. 2013, 40, 5521-5525. [CrossRef]

36. Zhou, X.; Matthes, H.; Rinke, A.; Klehmet, K.; Heim, B.; Dorn, W.; Klaus, D.; Dethloff, K.; Rockel, B. Evaluation of Arctic Land Snow Cover Characteristics, Surface Albedo, and Temperature during the Transition Seasons from Regional Climate Model Simulations and Satellite Data. Adv. Meteorol. 2014, 2014. [CrossRef]

37. Sahana, M.; Ahmed, R.; Sajjad, H. Analyzing land surface temperature distribution in response to land use/land cover change using split window algorithm and spectral radiance model in Sundarban Biosphere Reserve, India. Modeling Earth Syst. Environ. 2016, 2, 81. [CrossRef]

38. John, J.; Bindu, G.; Srimuruganandam, B.; Wadhwa, A.; Rajan, P. Land use/land cover and land surface temperature analysis in Wayanad district, India, using satellite imagery. Ann. GIS 2020, 26, 343-360. [CrossRef]

39. Hua, A.K.; Ping, W.W. The influence of land-use/cover changes on land surface temperature: A case study of Kuala Lumpur metropolitan city. Eur. J. Remote Sens. 2018, 2, 1049-1069. [CrossRef]

40. Pal, S.; Ziaul, S. Detection of land use and land cover change and land surface temperature in English Bazar urban centre. Egypt. J. Remote Sens. Space Sci. 2017, 20, 125-145. [CrossRef] 